\title{
EFFECT OF SEDENTARY LIFESTYLE ON CARDIORESPIRATORY FITNESS IN PHYSIOTHERAPY STUDENTS DURING LOCKDOWN PERIOD OF PANDEMIC COVID-19 \\ Dr. Chaitany Patel ${ }^{1}$, Vruti Patel ${ }^{2}$, Charmi Patel ${ }^{3}$
}

${ }^{1}$ Assistant Professor, Shree B. G. Patel College of Physiotherapy

${ }^{2,3}$ Internee, Shree B. G. Patel College of Physiotherapy

Shree B. G. Patel College of Physiotherapy, Affiliated to Sardar Patel University, Anand

\section{Corresponding author: chaitnay.bpt@gmail.com}

\begin{abstract}
:
Introduction: Sedentary behavior is associated with deleterious health outcomes, which differ from those that can be attributed to a lack of moderate to vigorous physical activity.

Methodology: - Experimental study design assigned by convenient sampling of 50 subjects. Outcome Measures: - Bruce protocol $\left(\mathbf{V O}_{2} \max \right)$ and category.

Result: - mean of pre and post values of $\mathrm{V}_{2} \mathrm{MAX}$ in Bruce protocol are $52.80 \mathrm{ml} / \mathrm{kg} / \mathrm{min}$ and 40.45 $\mathrm{ml} / \mathrm{kg} / \mathrm{min}$ respectively and SD of pre and post values are 8.61 and 6.71, respectively and before lockdown $82 \%$ subjects completed stage 4 and $28 \%$ completed stage 5 of Bruce protocol. After lockdown $28 \%$ subjects completed stage 4 and $2 \%$ completed stage 5 of Bruce protocol.

Conclusion: - There is a significance difference in cardio respiratory fitness due to sedentary lifestyle in respective of stages of completion of Bruce protocol and vo2 max. Within 70 days of sedentary behavior there is a declination of $30 \% \mathrm{VO}_{2}$ max.
\end{abstract}

Key words: Sedentary lifestyle, covid-19, cardiopulmonary fitness, Bruce protocol, physiotherapy

\section{INTRODUCTION:}

Sedentary behavior is associated with deleterious health outcomes, which differ from those that can be attributed to a lack of moderate to vigorous physical activity. This has led to the field of "sedentary physiology" which may be considered as separate and distinct from exercise physiology. A distinct class of behaviors (e.g., sitting, watching T.V., driving) characterized by little physical movement and low energy expenditure
(1.5 METs). MET is used to assess the energy expenditure during activities. (1)

The inactive life situation brought the sedentary lifestyle to the individual. The sedentary life process is influenced in the deterioration of the body metabolism of the individual. ${ }^{[2]}$ 


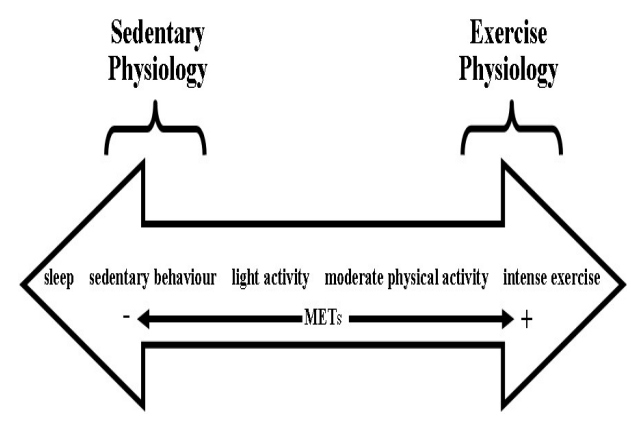

Fig.1: The movement continuum, illustrating the different focus of sedentary physiology and exercise physiology. METs, metabolic equivalent tasks. ${ }^{[1]}$

Enhance sedentary lifestyle by most common Factors like age, gender, technical advancement, and socio economic status ${ }^{[1]}$

In one study shows During the two weeks baseline period, the average number of hours of sedentary behavior was 9.1 hours per day. ${ }^{\text {[7] }}$

Physical inactivity as a major public health problem and a second leading cause of death due to cardiovascular impairment. On the average, adults spend 170 minutes per day on TV watching which amounts to $8.6 \%$ of daily total energy expenditure, $10.9 \%$ of daily energy is spent on driving and 55$57 \%$ of total daily energy on other sedentary behaviors like computer operation, video games, reading of books or sleeping. These activities do not enhance muscular/vigorous activities and so favor cardio-vascular diseases such as
Ischemic heart disease, coronary artery disease, stroke, among others. (8-10) $\mathrm{VO}_{2}$ max declines approximately 0.4 $\mathrm{ml} / \mathrm{kg} / \mathrm{min}$ each year for most individuals (4.0 $\mathrm{ml} / \mathrm{kg} / \mathrm{min}$ each decade). Sedentary individuals may have nearly twofold faster rates of decline. In $\mathrm{VO}_{2}$ maxaging. Heredity undoubtedly plays an important role, as does the well documented decrement in muscle mass with age. ${ }^{(10)}$ In Pandemic Covid - 19, There is a new public health crisis threatening the world with the emergence and spread of 2019 novel corona virus. The virus originated in bats and was transmitted to humans in Wuhan, China in December 2019.(4)

PHASES OF LOCKDOWN IN GUJARAT:(4)

PHASE 1: 25 March 2020 TO 14 April 2020 (21 days)

PHASE 2: 15 April 2020 TO 3 May 2020 (19 days)

PHASE 3: 4 May 2020 TO 17 May 2020 (14 days)

PHASE 4: 18 May 2020 TO 31 May 2020 (14 days)

Overall days: 70 Days

In pandemic covid - 19, overall, all age group of people are sedentary so we get to see the effect of sedentary behavior on cardiopulmonary fitness. 


\section{METHODOLOGY}

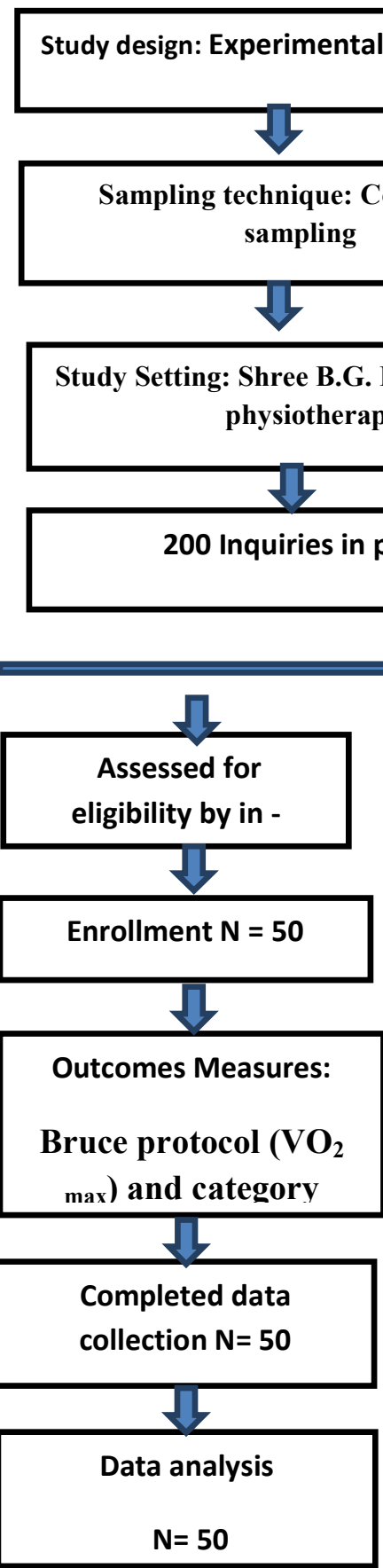

Excluded form in - person screen $\mathrm{N}=150$,Because they did not meet the inclusion criteria

Inclusion criteria: -

- Age: 19 to 23 years

- Gender: males and females

- Profession: young Physiotherapists

- An exercise heart rate $\geq 90 \%$ of subject age predicted maximum

- Voluntary exhaustion

Exclusion Criteria: -

- Age: <18 and >23 years

- Cardio-metabolic disease

- Smokers

- Cardio-respiratory disease

\section{PROCEDURE}

Subjects were selected on the basis of inclusion and exclusion criteria.

Demographic data in form of age, gender, height, and weight were collected. Pre and post intervention were assessed by bruce protocol in thatBegun with stage 1 with walking slowly foe 3 minutes at 2.7 $\mathrm{km} / \mathrm{hr}$ at a $10 \%$ grade (inclination).Speed and grade then increased in every stage of 3 minutes and end at stage 7 or till exhaustion.

$\mathrm{VO}_{2}$ max was estimated using the Bruce protocol.

CALCULATE VO丶MAX AND METABOLIC EQUIVALENT (MET):

Men: $\mathrm{VO}_{2} \max =14.8-(1.379 \times \mathrm{T})+$ $\left(0.451 \times \mathrm{T}^{2}\right)-\left(0.012 \times \mathrm{T}^{3}\right)$

Women: $\mathrm{VO}_{2} \max =4.38 \times \mathrm{T}-3.90$

MET: Divide $\mathrm{VO}_{2} \max$ by $3.5 \mathrm{ml} / \mathrm{kg} / \mathrm{min}$

$\mathrm{T}=$ Total time on the treadmill measured as a fraction of the minutes (That is a test time of 9 minutes 30 seconds would be written as $\mathrm{T}=9.5$ )

\section{STASTISTICAL ANALYSIS:}

Paired T test was used at end of the study. Null hypothesis will be rejected if $\mathrm{P}<0.05$. All the statistical analysis was conducted with the help of version 16.28 of the SPSS.

\section{DATA ANALYSIS:}

Total 50 subjects were included in the study depending on which following 
distribution is observed and in that gender ration is male is $28 \%$ and female is $72 \%$

SHOWS THE DEMOGRAPHIC DATA

\begin{tabular}{|c|c|}
\hline VARIABLES & MEAN \pm SD \\
\hline AGE $($ years $)$ & $21.65 \pm 1.01$ \\
\hline HEIGHT $(\mathrm{cm})$ & $159.44 \pm 7.45$ \\
\hline WEIGHT $(\mathrm{kg})$ & $54.57 \pm 9.0$ \\
\hline BMI $\left(\mathrm{kg} . \mathrm{m}^{2}\right)$ & $21.61 \pm 2.9$ \\
\hline
\end{tabular}

TABLE NO.1: - COMPARISON OF CATAGORIES OF PRE AND POST $\underline{\text { VO}}_{2}$ MAX

\begin{tabular}{|c|c|c|c|c|}
\hline \multirow{2}{*}{ CATAGORY } & \multicolumn{2}{|c|}{ PRE } & \multicolumn{2}{c|}{ POST } \\
\cline { 2 - 5 } & MALE & FEMALE & MALE & FEMALE \\
\hline SUPERIOR & 5 & 7 & 0 & 0 \\
\hline EXCELLENT & 6 & 19 & 1 & 4 \\
\hline $\begin{array}{c}\text { ABOVE } \\
\text { AVERAGE }\end{array}$ & 3 & 2 & 1 & 11 \\
\hline AVERAGE & 0 & 4 & 7 & 7 \\
\hline $\begin{array}{c}\text { BELOW } \\
\text { AVERAGE }\end{array}$ & 0 & 3 & 2 & 10 \\
\hline POOR & 0 & 0 & 3 & 1 \\
\hline VERY POOR & 0 & 1 & 0 & 3 \\
\hline
\end{tabular}

\section{STAGES COMPLETED} BY SUBJECTS

before lockdown a after lockdown

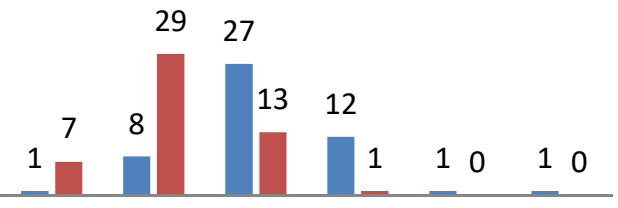

stage 2 stage 3 stage 4 stage 5 stage 6 stage 7

GRAPH NO.1: STAGES COMPLETED BY

SUBJECTS BEFORE AND

AFTERLOCKDOWN $\underline{\text { TABLE NO.2 }}$

COMPARISON OF PRE AND POST

VALUE OF VO 2 MAX CALCULATED

BY BRUCE PROTOCOL

\begin{tabular}{|c|c|c|c|c|c|}
\hline OUTC & PRE & POST & D & T & P \\
OME & MEA & MEA & F & VA & VAL \\
& N \pm SD) & N \pm SD) & & LUE & UE \\
\hline VO2 & $52.80 \pm$ & $40.45 \pm$ & 3 & 16.2 & $<0.0$ \\
MAX & 8.61 & 6.71 & 9 & 2 & $001^{*}$ \\
\hline
\end{tabular}

*Sign shows: Significant difference

\section{RESULTS}

In this study pre and post value of $\mathrm{vo}_{2} \max$ calculated by Bruce protocol divided in to seven different categories. In pre phase major male subjects fall in superior and excellent categories while major female subjects fall in excellent category. In post phase major male subjects fall in average category while major female subjects fall in above to below average categories.

In this study before lockdown $82 \%$ subjects completed stage 4 and $28 \%$ completed stage 5 of Bruce protocol. After lockdown $28 \%$ subjects completed stage 4 and $2 \%$ completed stage 5 of Bruce protocol.

\section{DISCUSSION}

The inactive life situation brought the sedentary lifestyle to the individual. Adults spend 170 minutes per day on TV watching which amounts to $8.6 \%$ of daily 
total energy expenditure, $10.9 \%$ of daily energy is spent on driving and $55-57 \%$ of total daily energy on other sedentary behaviors likes computer operation, video games, reading of books or sleeping. These activities do not enhance muscular/vigorous activities and so favor cardio-vascular diseases such as Ischemic heart disease, coronary artery disease, stroke, among others. Cardiovascular diseases have behavioral correlates and that physical inactivity is related to cardiovascular disease. ${ }^{[2]}$

In healthy sedentary people, heart rate should increase with exercise and reach to normal values in recovery phase. It was observed that the heart rate increased in the male and female group and the heart rate decreased in the recovery period, but the resting heart rate could not be reached. This can be explained by the fact that the cardiovascular capacities of sedentary persons are lower than those who are trained. Because with training, occurs a decrease in the rate of heart. This means that the trained heart will work less for the same job than for the non-trained heart. ${ }^{[5]}$

In this study, before lockdown $82 \%$ subjects completed stage 4 and $28 \%$ subjects completed stage 5 of BRUCE PROTOCO. After lockdown 28\% subjects completed stage 4 and $2 \%$ subjects completed stage 5 of BRUCE

\section{PROTOCOL.}

V02 max normally declines with ageing, at a rate of about $9 \%$ per decade for physically inactive people. The rate of decline is substantially slowed (to about $5 \%$ ) in those who practice a physically active lifestyle ${ }^{[10]}$

Failure continues to monitor therapy.

If $\mathrm{VO}_{2} \max <6 \%$ change then heart failure possibly deteriorating, consider alternative therapies. ${ }^{[12]}$

CONCLUSION: There is a significance difference in cardio respiratory fitness due to sedentary lifestyle in respective of stages of completion of Bruce protocol and vo2 max. Within 70 days of sedentary behavior there is a declination of $30 \% \mathrm{VO}_{2}$ $\max$.

FUTURE RESEARCH: Same study with a large population. In our study there is lack of correlation between vo2max and gender, vo2max and BMI. Experimental study like effect of education in sedentary behavior and only exercise for cardio respiratory fitness. Same study follows up in subjects after joining the professional curriculum within 3 months.

Same study amongst different occupation.

\section{REFERENCES}

1. Mark Stephen Tremblay, et all (2010) Physiological and health implication of sedentary lifestyle.Appl. Physiol. 
Nutra. Metab. 35: 725-740 (2010) doi:10.1139/H10-079

2. Dr.Mfrekemfon.P.Inyang,et all (2015) Sedentary Lifestyle: Health implication. IOSR Journal of Nursing and Health Science (IOSR-JNHS) eISSN: 2320-1959.p- ISSN: 2320-1940 Volume 4, Issue 2 Ver. I (Mar.-Apr. 2015), PP 20-25

3. A.D.P. Bankoff, et all (2013) Study on little active and sedentary women: Comparison between protocols and prospects for admission in physical activity program. Open journal of preventive medicine, Vol.3, No.6, 413419(2013)http://dx.doi.org/10.4236/ojp $\underline{\mathrm{m} .2013 .36056}$

4. Tanusinghal (2019) A Review of Coronavirus Disease-2019 (COVID19), The Indian Journal of Pediatrics (April 2020) 87(4):281286https://doi.org/10.1007/s12098$\underline{020-03263-6}$

5. Betulakyol,et all (2018) Investigation of Cardiovascular Endurance Levels of Sedentary High School Students, Journal of Education and Training Studies Vol. 6, No. 5; May 2018 ISSN 2324-805X E-ISSN 2324-8068 URL: http://jets.redfame.com

6. Ekta Khurana, et all (2016) Determination of cardiovascular fitness in young healthy medical students,
International Archives of Integrated Medicine, Vol. 3, Issue 10, October 2016. ISSN: 2394-0026 (P) ISSN: 2394-0034 (O) http://iaimjournal.com/

7. Peter John de Chavez, et all (2018) The effect of changes in physical activity on sedentary behavior: results from a randomized lifestyle intervention trial. Am $\mathrm{J}$ Health Promote, July 2017; 31(4):287-295. Doi: $\quad$ 10.4278/ajhp.150129-QUAN693.

8. L. A. Steinhaus, et all,(1998) Cardiorespiratory fitness of young and older active and sedentary men.Brit.J. Sports Med. - Vol. 22, No. 4, December 1988, pp. 163-166

9. Ann M. Swank, (2012) Modest Increase in Peak VO2 is Related to Better Clinical Outcomes in Chronic Heart Failure Patients: Results from Heart Failure and a Controlled Trial to Investigate Outcomes of Exercise Training (HF-ACTION)

10. Ann M. Swank, (2012) Modest Increase in Peak VO2 is Related to Better Clinical Outcomes in Chronic Heart Failure Patients: Results from Heart Failure and a Controlled Trial to Investigate Outcomes of Exercise Training (HF-ACTION) 